\title{
Beyond reduction of atherosclerosis: PON2 provides apoptosis resistance and stabilizes tumor cells
}

\author{
I Witte ${ }^{1,3}$, S Altenhöfer ${ }^{1,3}$, P Wilgenbus ${ }^{1}$, J Amort ${ }^{1}$, AM Clement ${ }^{2}$, A Pautz ${ }^{1}, \mathrm{H} \mathrm{Li}^{1}$, U Förstermann ${ }^{1}$ and S Horke ${ }^{\star, 1}$
}

Major contributors to atherosclerosis are oxidative damage and endoplasmic reticulum (ER) stress-induced apoptosis; both of which can be diminished by the anti-oxidative protein paraoxonase-2 (PON2). ER stress is also relevant to cancer and associated with anti-cancer treatment resistance. Hence, we addressed, for the first time, whether PON2 contributes to tumorigenesis and apoptotic escape. Intriguingly, we found that several human tumors upregulated PON2 and such overexpression provided resistance to different chemotherapeutics (imatinib, doxorubicine, staurosporine, or actinomycin) in cell culture models. This was reversed after PON2 knock-down. Remarkably, just deficiency of PON2 caused apoptosis of selective tumor cells per se, demonstrating a previously unanticipated oncogenic function. We found a dual mechanistic role. During ER stress, high PON2 levels lowered redox-triggered induction of pro-apoptotic CHOP particularly via the JNK pathway, which prevented mitochondrial cell death signaling. Apart from CHOP, PON2 also diminished intrinsic apoptosis as it prevented mitochondrial superoxide formation, cardiolipin peroxidation, cytochrome $c$ release, and caspase activation. Ligand-stimulated apoptosis by TRAIL or TNF $\alpha$ remained unchanged. Finally, PON2 knock-down caused vast reactive oxygen species formation and stimulated JNK-triggered CHOP expression, but inhibition of JNK signaling did not prevent cell death, demonstrating the pleiotropic, dominating anti-oxidative effect of PON2. Therefore, targeting redox balance is powerful to induce selective tumor cell death and proposes PON2 as new putative anti-tumor candidate.

Cell Death and Disease (2011) 2, e112; doi:10.1038/cddis.2010.91; published online 13 January 2011

Subject Category: Internal Medicine

Cell death can be induced by ligand-receptor interactions, designated as extrinsic apoptotic pathway, whereas intrinsic signaling results from intracellular malfunctions. Protein (dys)functions may be discriminated from organelle-based pathways, such as stress at the endoplasmic reticulum (ER), or nuclear DNA damage. These pathways intersect and impact on cell death, which contributes to numerous human illnesses characterized either by excessive cell death, or resistance to apoptosis. Knowledge of crucial factors and steps is critical as their effects may be both appreciated and detrimental.

Many newly synthesized proteins pass the ER and require sumptuous modifications. Any disturbance induces ER stress and activates the unfolded protein response (UPR) pathway. Although its primary goal is to assist cell survival, this pathway can ultimately initiate cell death and relates to atherosclerosis, diabetes, or neurodegeneration. ${ }^{1}$ Additionally, the UPR is critically engaged in the balance between apoptosis or outgrowth of cancer cells ${ }^{2}$ and therefore therapeutically targeted. The UPR is a defined progression of events involving only few ER transmembrane proteins: (I) activation of the kinase PERK; this phosphorylates elF2a, which induces transcription factor ATF4 and blocks translation; (II) activation of IRE1, which triggers protein kinase JNK and produces transcription factor XBP1 by an unconventional splicing event; and (III) processing and activation of ATF6. ${ }^{1}$ This leads to transcriptional induction of chaperones and the pro-apoptotic CHOP protein. In case of insurmountable ER stress, CHOP fundamentally initiates apoptosis, as highlighted by the fact that $\mathrm{CHOP}$ deficiency enhanced resistance to diverse cytotoxic stimuli. ${ }^{3,4}$

Also, mitochondria are centrally involved in the execution of cell death. Upon receiving toxic stimuli mitochondria produce excess reactive oxygen species (ROS), that is, superoxide $\mathrm{O}_{2}^{-}$. Spontaneous or catalyzed dismutation of $\mathrm{O}_{2}^{-}$generates $\mathrm{H}_{2} \mathrm{O}_{2}$. This is a substrate for cytochrome $c$, which in turn catalyzes the $\mathrm{H}_{2} \mathrm{O}_{2}$-dependent peroxidation of cardiolipin, a lipid found almost exclusively at the inner mitochondrial membrane. Cardiolipin peroxidation causes mitochondrial cytochrome $c$ release, which promotes apoptosome formation and links ROS production with apoptosis. ${ }^{5}$ Importantly, we showed that the human enzyme paraoxonase-2 (PON2) diminished not only ROS but also ER stress-induced apoptosis. $^{6}$

\footnotetext{
${ }^{1}$ Institute of Pharmacology, University Medical Center, Obere Zahlbacher Street 67, Mainz, Germany; ${ }^{2}$ Institute of Pathobiochemistry, Duesbergweg 6, University Medical Center, Mainz, Germany

${ }^{*}$ Corresponding author: S Horke, Institute of Pharmacology, University Medical Center, Obere Zahlbacher Street 67, Mainz 55131, Germany. Tel: + 49 613 1179196 ; Fax: + 496131393 6611; E-mail: horke@uni-mainz.de

${ }^{3}$ These authors contributed equally to this work.

Keywords: paraoxonase; apoptosis; endoplasmic reticulum stress; mitochondria; oxidative stress; CHOP

Abbreviations: ALL, acute lymphoblastic leukemia; ATF, activating transcription factor; CHOP, C/EBP homologous protein (growth arrest/DNA-damage inducible gene 153, GADD153); CML, chronic myeloid leukemia; elF2 $\alpha$, eukaryotic initiation factor $2 \alpha$; ER, endoplasmic reticulum; IRE1, inositol requiring enzyme 1; JNK, c-Jun N-terminal kinase; NAC, N-acetyl cysteine; PERK, PKR-like ER kinase; PON, paraoxonase; ROS, reactive oxygen species; SOD, superoxide dismutase; TNF $\alpha$, Tumor necrosis factor $\alpha$; TRAIL, Tumor Necrosis Factor Related Apoptosis Inducing Ligand; UPR, unfolded protein response; XBP, X-box binding protein

Received 03.11.10; accepted 18.11.10; Edited by M Federici
} 
PON2 is one of three highly conserved members of the paraoxonase family of enzymes consisting of PON1, PON2, and PON3. In contrast to PON1 and PON3, PON2 is not present in serum lipoprotein fractions, but an intracellular protein found in almost every tissue, particularly at the perinuclear region, ER and mitochondria. ${ }^{6-8}$ Again contrasting with PON1, PON2 shows predominant lactonase activity. ${ }^{9-11}$ Natural substrates remain unknown albeit PON2, as part of the innate immune system, appears involved in the defense against infections by the human pathogen Pseudomonas aeruginosa. ${ }^{12-14}$ Paraoxonases are important detoxifying and anti-oxidative enzymes, which establishes their role in organophosphate poisoning, diabetes, obesity, cardiovascular diseases, and innate immunity. ${ }^{11,15}$ In mice, PON levels negatively correlated with atherosclerosis. ${ }^{16-18}$ Consistently, several studies demonstrated that PON2 protected macrophages, vascular and other cells against oxidative stress, whereas its downregulation reversed this effect. $6,7,19$ The cytoprotective effect of PON2 is well established. However, it is fully enigmatic how PON2 reduced apoptosis, whether this is restricted to certain pathways and what the pathophysiological relevance could be. These issues are addressed in this study.

Although neglected and not primarily addressing PONs, some (microarray) studies observed marked overexpression of PON2 in cancers, for example, in hepatocellular carcinoma, ${ }^{20}$ prostate carcinoma ${ }^{21}$ or lymphocytes infected with $\mathrm{T}$ cell leukemia virus ${ }^{22}$ PON2 was also highly upregulated in gene expression profiling studies addressing pediatric acute lymphoblastic leukemia (ALL). ${ }^{23}$ In another study, PON2 was among a small group of upregulated genes that characterized pediatric ALL patients with very poor outcome prognosis and the potential to prospectively identify patients who fail current therapeutic regimens. ${ }^{24}$ Interestingly, PON2 was also present in an outcome-specific gene expression signature that characterized chronic myeloid leukemia (CML) patients resistant to front-line therapeutic imatinib. ${ }^{25}$ Given the antiapoptotic role of PON2 ${ }^{6,26}$ and the fact that apoptotic escape represents a major clinical complication, we asked whether PON2 overexpression contributes to cancer as it confers apoptosis resistance. This is the first report that investigates the expression of PON2 in various human tumor samples, its involvement in cancer cell signaling and impact on cytotoxicity of chemotherapeutics. Our results are of great importance, given that targeting of redox balance in tumors recently turned into an attractive and very potent tool in cancer therapy.

\section{Results}

PON2 is overexpressed in tumors and its knock-down causes death of selective tumor cells. PON2 overexpression, in contrast to its knock-down, diminished ER stress-induced cell death and prevented mitochondrial superoxide production. ${ }^{6,26-28}$ The latter regulates cytochrome $c$ liberation from mitochondria ${ }^{5}$ and may thus, explain how PON2 counteracts atherosclerosis, for example, by protecting vascular cells and macrophages from cell death. However, potential drawbacks of this cytoprotective effect or diseases other than atherosclerosis have never been tested. Cancer appeared relevant, because effects such as that of PON2 are frequently exploited by tumors. Therefore, we analyzed PON2 cDNA levels in cancer survey panels covering $>430$ different samples from various normal versus diseased tissues (Figure 1a). Although no augmented PON2 levels were observed in some cases, moderate overexpression ( $\sim 1.5$-fold) was seen in tumors of thyroid gland, prostate, pancreas, and testis. Higher PON2 levels were found in tumors from endometrium/uterus, liver, kidney, lymphoid tissues, or urinary bladder ( 2-4-fold). An upregulation of PON2 and its relevance are supported by recent studies that found high PON2 levels in association with poor prognosis in cohorts of pediatric $\mathrm{ALL}^{23,24}$ or with imatinib resistance in CML patients. ${ }^{25}$ We next analyzed protein expression in selected lysates from pools of normal versus tumor tissues (Figure 1b). No upregulation was seen in spleen tumors, and a moderate PON2 overexpression in pancreas and lung tumors. In concordance with above cDNA panels, kidney and liver tumors doubled PON2 protein levels. Over 10-fold upregulation of PON2 was found in thymus tumors and non-Hodgkins lymphomas (the latter is 1.7-fold when normalized to lymph node instead of peripheral leukocytes).

We hypothesized that PON2 contributes to apoptotic escape of tumor cells and tested whether chemotherapeutictriggered cell death correlated with its expression level. Indeed, stable overexpression of PON2-GFP or PON2-HA in endothelial cells reduced the dose-dependent activation of caspase- 3 and intracellular ATP decrease in response to the anthracycline doxorubicin (Figure 1c). Similarly, increased PON2 levels prevented death of Bcr-Abl-positive K562 leukemia cells in response to front-line therapeutic imatinib, a Bcr-Abl kinase inhibitor (Figure 1d). This likely explains the contribution of PON2 to imatinib resistance in primary resistant CML patients. ${ }^{25}$ As PON2 upregulation provided apoptotic escape (Figures 1c and $d$ and below), we tested whether PON2 deficiency reversed this effect to enhance susceptibility to chemotherapeutics. Indeed, RNAi-mediated knock-down of PON2 was even additive to imatinib-triggered K562 cell death and enhanced apoptosis rates (Figure 1e and Supplementary Figure s1A). Strikingly, however, we observed that just PON2 knock-down caused significant cell death even in the absence of pro-apoptotic stimulation (Figure 1e), which was unexpected given the viability of PON2-deficient mice. To expand this to other tumor cell lines, PON2 was knocked down in K562 leukemia cells, A549 lung carcinoma cells, endothelial EA.hy 926 cells, Huh7 and HepG2 hepatoma cells, embryonic kidney HEK293 cells, and Jurkat T-cell leukemia cells. We analyzed, 3 days later, apoptosis rates by flow cytometry (Figure $1 \mathrm{f}$ and Supplementary Figure s1A). Huh7 (or HepG2; not shown), Jurkat, and HEK293 cells did not react to PON2 knock-down. This contrasts with severely increased apoptosis of K562, A549, and EA.hy 926 cells. As apoptosis required no further stimulation to proceed, we revealed an unanticipated oncogenic role for PON2, apparently of special importance for leukemias or lung cancer. Therefore, we next addressed its mechanism.

PON2 reduces UPR-triggered induction of pro-apoptotic CHOP. Previous data linked PON2 with ER stress-induced cell death. ${ }^{6,26}$ To discriminate apoptotic pathways and reveal 
a

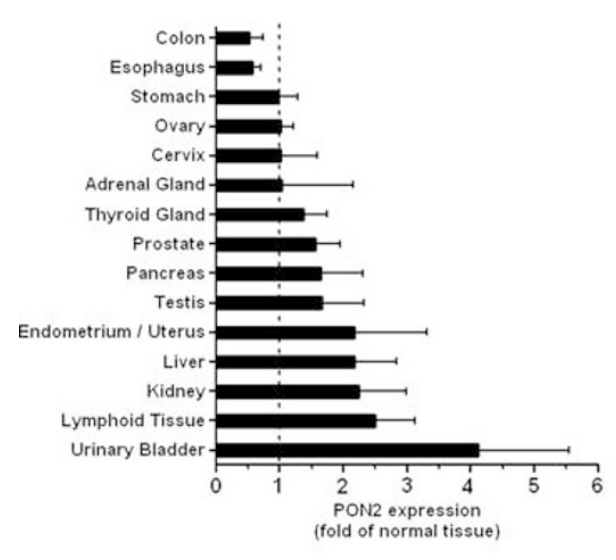

C

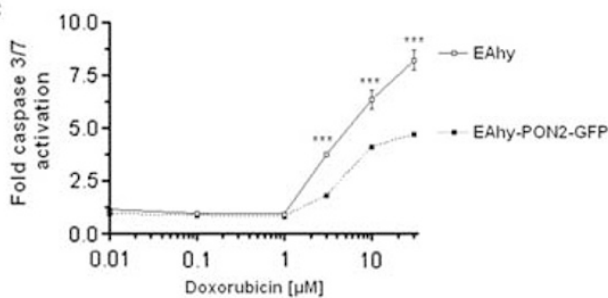

d

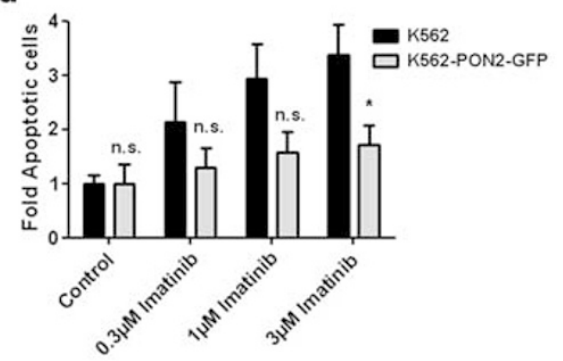

b
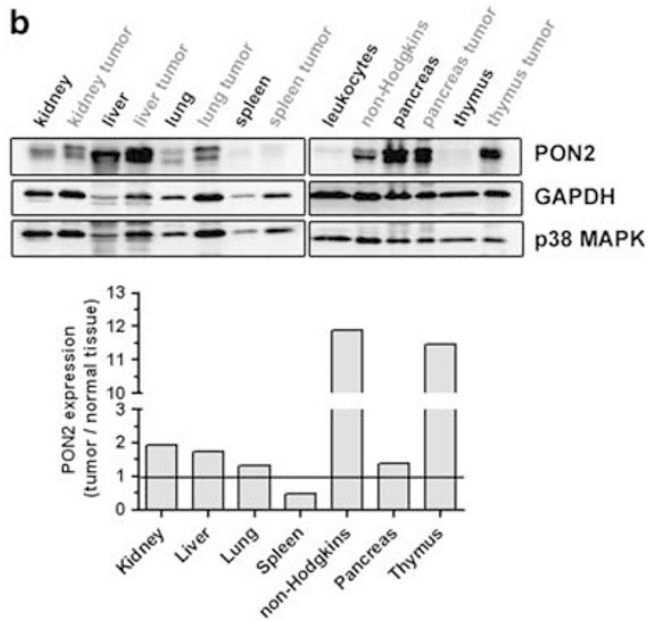
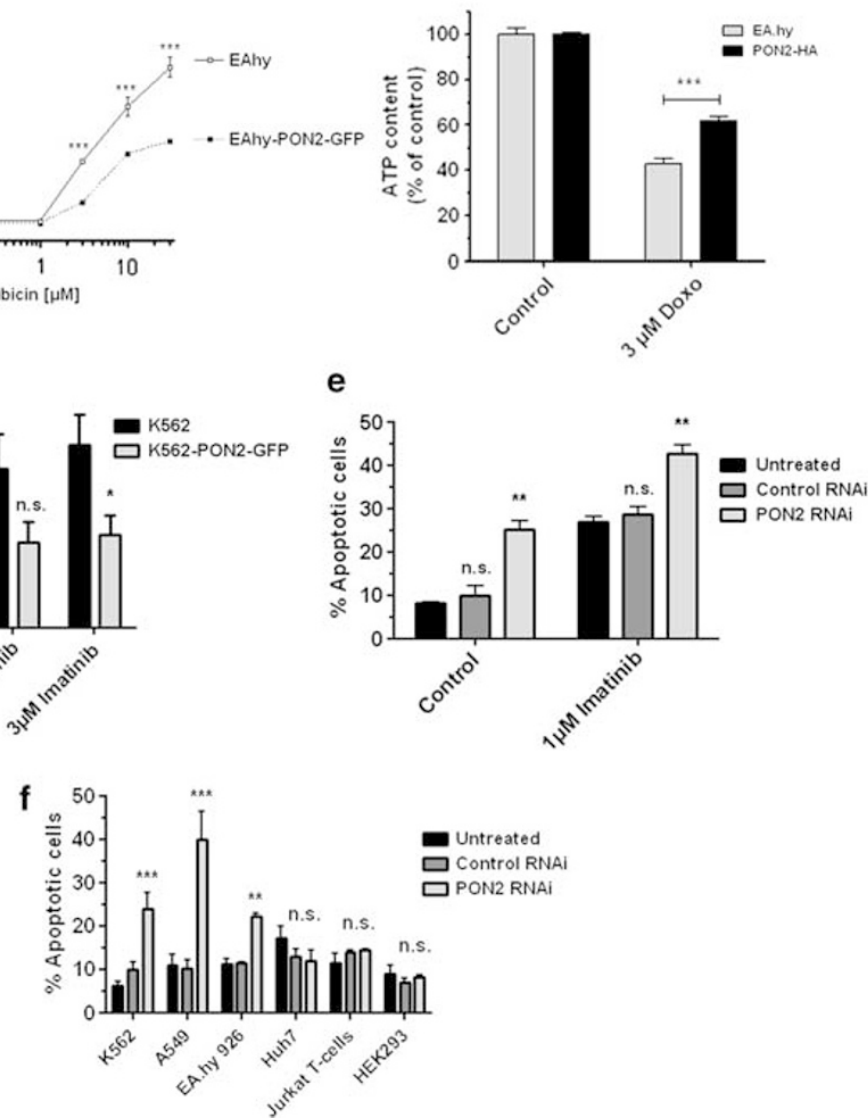

Figure 1 PON2 is overexpressed in several tumors and its deficiency causes death of some tumor cells. (a) PON2 cDNA expression levels were determined in cancer versus normal tissues by quantitative real-time PCR using TissueScan cancer survey/lymphoma panels containing $>430$ samples from various tumors. (b) Mixed donor samples from the indicated primary healthy or tumor tissues were analyzed for PON2, GAPDH, and p38MAPK expression by western blotting. Lower panel shows quantitative evaluation. The 12-fold upregulation in non-Hodgkins lymphoma is 1.7-fold when normalized to lymph node instead of peripheral leukocytes. (c) Endothelial EA.hy 926 cells were stimulated with the indicated concentrations of doxorubicin and assessed for caspase-3/7 activity (left; $16 \mathrm{~h}$ ) or intracellular ATP level (right; $24 \mathrm{~h}$ ). (d) K562 cells were left untreated or were transfected with PON2-GFP. Next day, the cells were treated for $24 \mathrm{~h}$ with imatinib and analyzed for cell death by flow cytometry. Only GFP-positive cells were counted and calculated as fold increase in apoptosis. GFP-transfected K562 behaved as untreated (not shown). (e) K562 cells were left untreated or were transfected with scrambled (control) or PON2-specific siRNAs. After 3 days, imatinib was added for $24 \mathrm{~h}$ and cells were analyzed as above. (f) Indicated cells were left untreated or were treated with scrambled or PON2-specific siRNAs. Three days later, cell death was assessed by FACS. Results for Huh7 cells were exchangeable with HepG2; Jurkat-T-cells did not express significant PON2 protein levels (not shown). Symbols represent mean \pm S.E.M.; $n=3-6$ (c-e); n.s. $=$ not significant; ${ }^{*} P<0.05 ;{ }^{* * *} P<0.001$

underlying mechanism(s), we first tested PON2's effect on transcriptional induction of CHOP, a very potent pro-apoptotic factor critically involved in ER stress (and below $^{3}$ ). Naive or PON2-GFP overexpressing cells were challenged with tunicamycin to induce ER stress. Tunicamycin time-dependently increased CHOP mRNA and 
protein levels, but this was substantially lower in PON2overexpressing cells (Figures $2 a$ and $b$ ). Given the impact of $\mathrm{CHOP}$ on cell death, this effect likely explains the protective role of PON2, at least in part and in response to ER stress. In order to test this hypothesis and because apoptotic efficacy of CHOP may relate to cell type and stimulus, CHOP was knocked down by siRNA (Figure 2c). Subsequently, we monitored tunicamycin-induced apoptotic processes. Figures 2d-f show that abrogated CHOP expression correlated with reduced levels of cardiolipin peroxidation, preserved mitochondrial membrane potential $\triangle \Psi \mathrm{M}$, absent nuclear condensation, and low caspase-3 activation. Hence, CHOP is centrally involved in signaling from ER to mitochondria and a decrease of its induction, as resembled by high PON2 levels, is sufficient to avert ER stress-induced apoptosis.

PON2 has an enzymatic lactonase activity and it reduces oxidative stress. To distinguish which function diminished $\mathrm{CHOP}$ induction, we used PON2 point-mutations $\mathrm{H}^{114} \mathrm{Q}$ or $H^{133} \mathrm{Q}$, as these blunted its lactonase, but not anti-oxidative activity. ${ }^{27}$ These PON2-mutants reduced CHOP induction and cell death indistinguishable from PON2-wildtype (see Figure $3 a$ for CHOP and ${ }^{27}$ for caspase-3 activation, intracellular ATP levels and apoptosis). This discloses PON2's antioxidative effect as basis for its anti-apoptotic function. Yet, there is no mutation known that abrogates PON2's impact on ROS, so we verified that established anti-oxidative mechanisms also attenuated $\mathrm{CHOP}$ expression. Naive cells were loaded with cell-permeable superoxide dismutase (PEGSOD; $100 \mathrm{U} / \mathrm{ml}$ ) or $\mathrm{N}$-acetyl cysteine (NAC; $10 \mathrm{~mm}$ ) $24 \mathrm{~h}$ before addition of tunicamycin. Both treatments diminished ROS production (not shown) and CHOP activation (Figures $3 \mathrm{~b}$ and $\mathrm{c}$ ), which confirms the impact of ROS secondary to ER stress.

\section{PON2 reduces CHOP induction by lowering JNK} signaling. We next addressed how PON2 decreased $\mathrm{CHOP}$ induction. First, we analyzed the c-Jun N-terminal kinase (JNK) pathway, because ER stress produces ROS that can activate $\mathrm{JNK},{ }^{29,30}$ which in turn can be upstream and downstream of the UPR and CHOP. Given that PON2 diminished ER stress-induced ROS and because antioxidants lowered CHOP induction (and above ${ }^{6}$ ), we suggested that PON2 decreased CHOP by acting on ROSactivated JNK. Indeed, tunicamycin-triggered JNK activation (i.e., $\mathrm{Thr}^{183} / \mathrm{Tyr}^{185}$ phosphorylation) was significantly lower in PON2-overexpressing cells (Figure 3d). Consequently, we verified that JNK inhibition reduced $\mathrm{CHOP}$ expression in naive but not PON2-overexpressing cells. This was assessed by pharmacological and genetic approaches. The JNK inhibitor SP600125 significantly lowered tunicamycin-triggered $\mathrm{CHOP}$ induction in naive cells (Figure $3 e$ ), demonstrating that in this system JNK is upstream of $\mathrm{CHOP}$ expression. This effect was absent in PON2 overexpressing cells (Figure $3 e$ ). JNK knock-down by siRNA also decreased CHOP induction in naive but not in PON2-overexpressing cells (Figure $3 f$ and Supplementary Figure S1B). Concordantly, CHOP induction in naive cells with SP600125 or JNK siRNA did not significantly differ from that in PON2-overexpressing cells without such stimulation.

Next, we verified the specificity of PON2 for the JNKCHOP-axis. CHOP induction in response to ER stress is mainly mediated by activation of the three UPR branches transduced by IRE1, PERK, and ATF6. To determine PERK activation, we measured elF2a phosphorylation and ATF4 induction. Figure $4 \mathrm{a}$ shows an increase in phospho-elF2a levels $2 \mathrm{~h}$ after tunicamycin addition, which gradually increased over time. This was identical in naive and PON2overexpressing cells. Further, PON2 overexpression did not alter induction of ATF4 mRNA or protein (Figure $4 \mathrm{~b}$ and not shown). In a similar manner, IRE1-mediated splicing of XBP1 mRNA was unaffected by PON2 overexpression (Figure 4c). Processing and thus activation of ATF6 by Site- 1 and Site- 2 proteases was also independent from PON2 levels (Figure 4d). Hence, we demonstrate that PON2 overexpression counteracts cell death by balancing ROS levels. During ER stress, this holds CHOP at bay and could be achieved as PON2 via ROS controls JNK activation (and not by acting on PERK, IRE1, or ATF6 signaling). In agreement with such model, PON2 knock-down is sufficient to induce vast ROS production (Figure 5a). Still in accord, it also causes moderate CHOP expression (Figure 5b), however, viability loss after PON2 knock-down is not prevented by inhibited JNK signaling (Figure 5c), which reveals that additional effects (disturbed mitochondrial redox homeostasis; see below) dominate over the induction of CHOP.

PON2 also protects against intrinsic apoptotic signaling. We next assessed PON2's effect on ER stressunrelated apoptosis. To this end, cells were treated with additional chemotherapeutics and established inducers of intrinsic apoptosis, such as PKC inhibitor staurosporine or transcription inhibitor actinomycin D. These compounds failed to induce CHOP (Supplementary Figure S1C), so effects are independent from this protein. Staurosporine treatment $(0.5 \mu \mathrm{M} ; 16 \mathrm{~h})$ caused pronounced apoptosis in naive cells $(\sim 77 \%)$, which was strongly reduced in PON2overexpressing cells ( 33\%; Figure 6a). A closely similar tendency was seen after actinomycin D treatment $(5 \mu \mathrm{g} / \mathrm{ml}$; $24 \mathrm{~h}$; Figure 6a). Given the protection afforded by higher PON2 levels, we traced upstream effects and monitored

\footnotetext{
Figure 2 PON2 reduces induction of pro-apoptotic CHOP. (a and $\mathbf{b})$ Naive or PON2-GFP overexpressing EA.hy 926 cells were treated with tunicamycin ( $1 \mu \mathrm{g} / \mathrm{ml})$ for the indicated time and analyzed for CHOP mRNA and protein levels $(A+B$, respectively). (c) Naïve EA.hy cells were left untreated (control), or transfected with scrambled or CHOP-specific siRNAs. Next day, cells were treated with solvent (left) or tunicamycin $(1 \mu \mathrm{g} / \mathrm{ml} ; 6 \mathrm{~h}$ ) and analyzed for CHOP and $\alpha$-tubulin protein levels. (d) Control or siRNAtreated naive cells were stimulated with tunicamycin $(1 \mu \mathrm{g} / \mathrm{ml} ; 48 \mathrm{~h})$ followed by cardiolipin staining by NAO and analysis by a fluometer. Fluorescence decrease indicates cardiolipin peroxidation. (e) Scrambled- or CHOP-siRNA-treated cells were tunicamycin-stimulated for $48 \mathrm{~h}$ and analyzed for caspase-3 activation. Symbols represent mean \pm S.E.M. $n=3-9 ; n$.s. $=$ not significant; ${ }^{* *} P<0.01$; ${ }^{* * *} P<0.001$. (f) Untreated or CHOP-siRNA treated cells were stimulated with tunicamycin as before (48 h), stained for mitochondrial membrane potential $\left(\triangle \Psi \mathrm{M} ;\right.$ by $\left.\mathrm{DiOC}_{6}\right)$ and nuclei, and analyzed by confocal laser-scanning microscopy. Arrows indicate cells with lost membrane potential and nuclear condensation. Images are representative of several others
} 


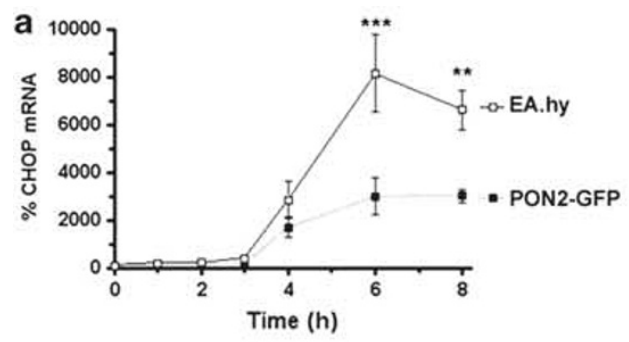

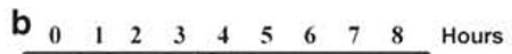
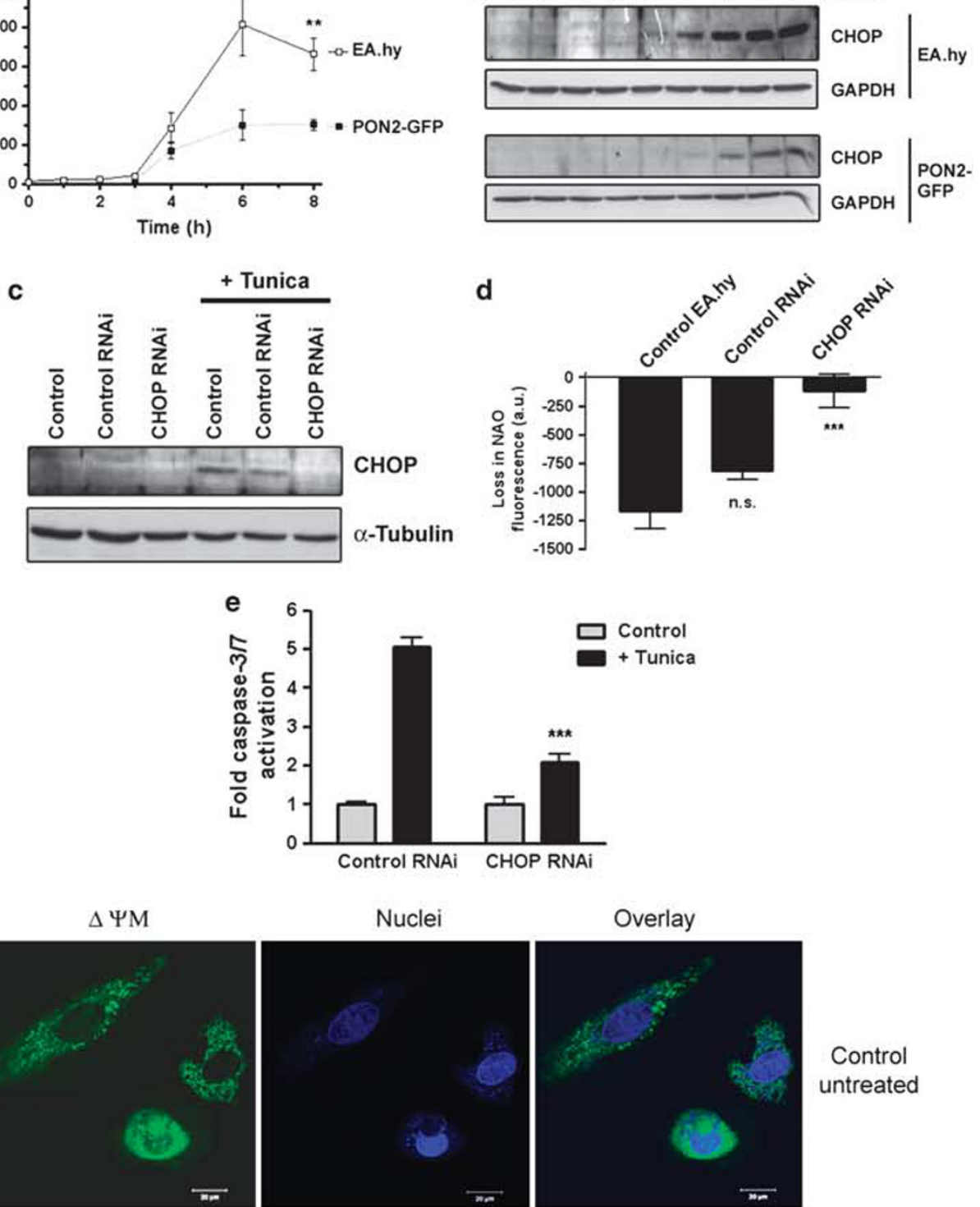

Control

untreated
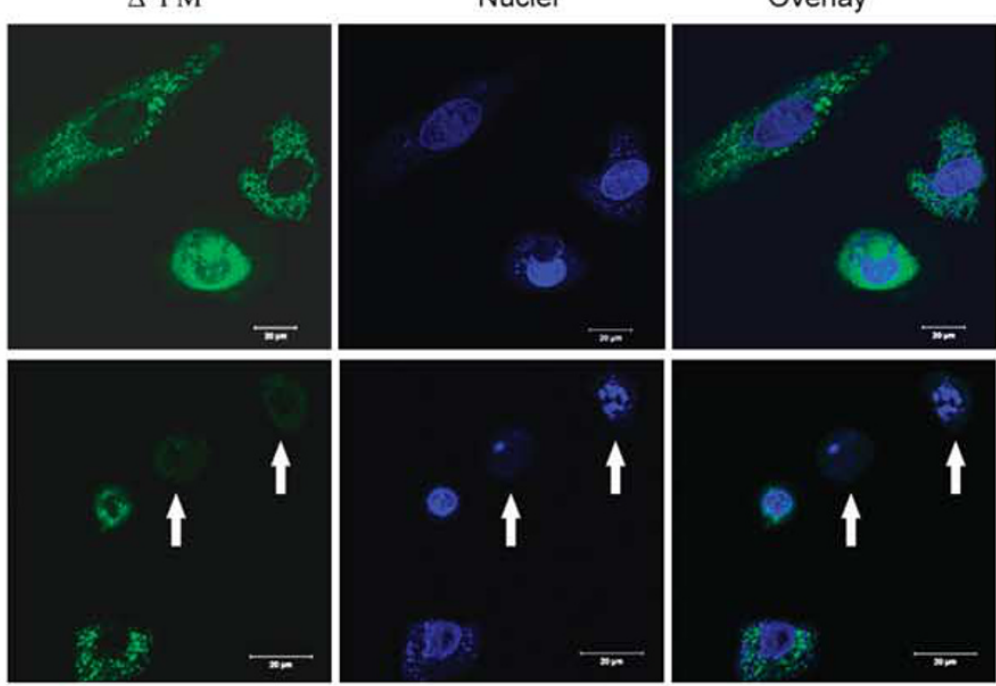

Control

ttunica
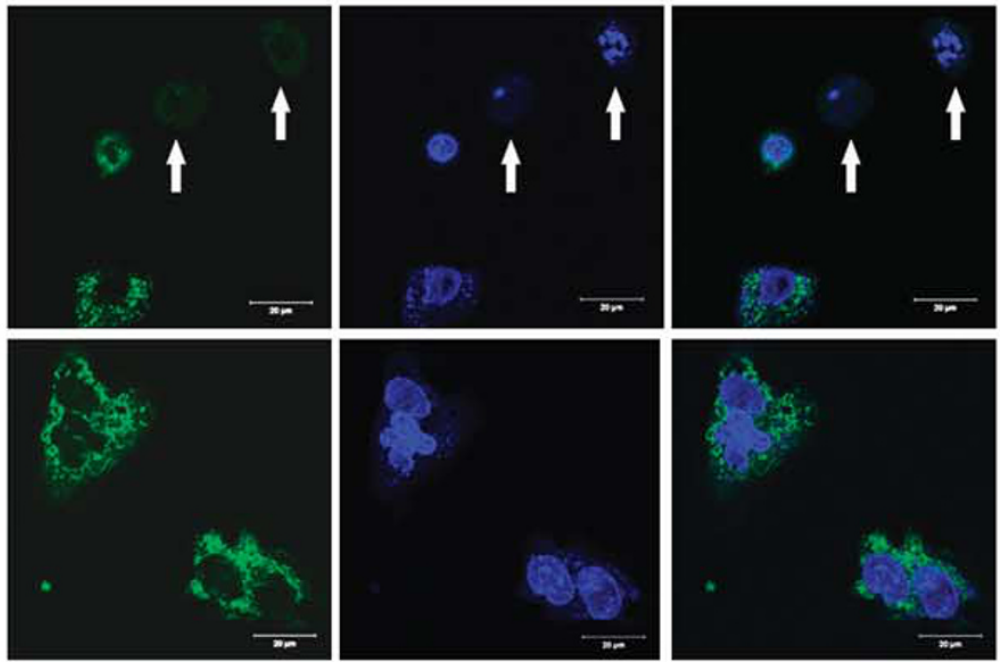

Chop RNAi

+tunica 

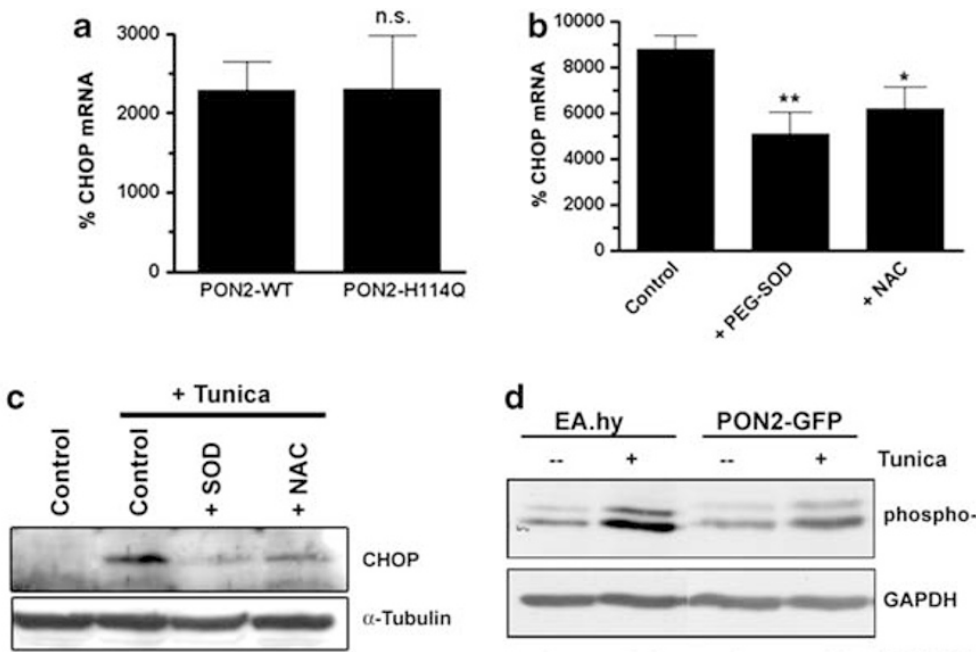

d
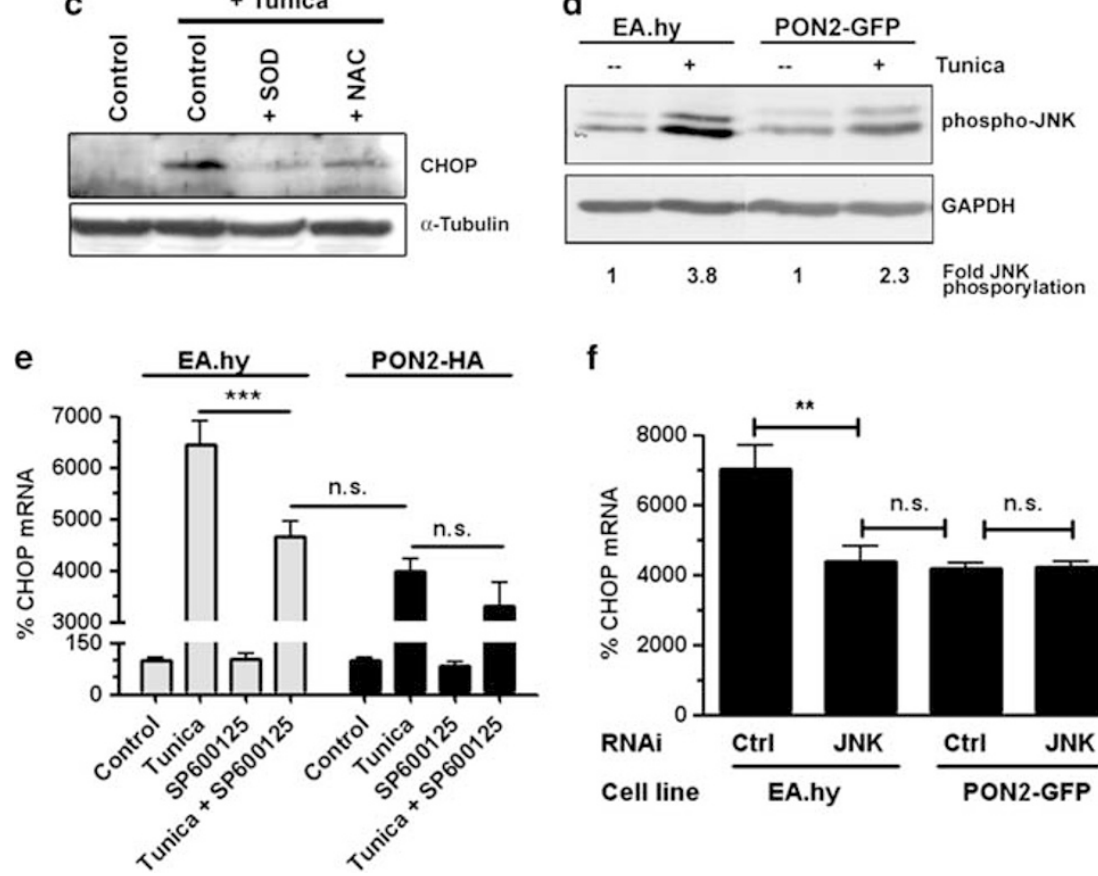

f

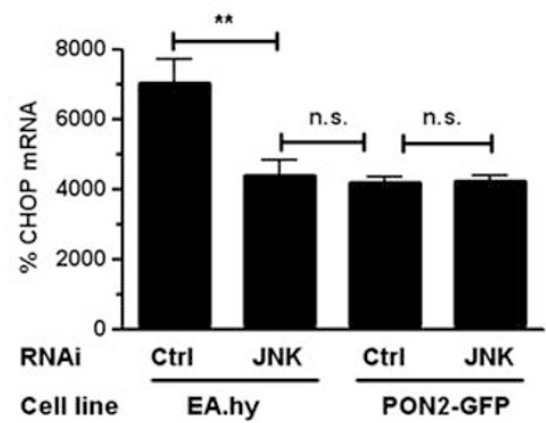

Figure 3 PON2 diminishes CHOP induction by lowering JNK activation. (a) Endothelial cells overexpressing PON2-WT-GFP or lactonase-deficient PON2-H ${ }^{114} \mathrm{Q}-\mathrm{GFP}$ were treated with tunicamycin $(1 \mu \mathrm{g} / \mathrm{ml} ; 8 \mathrm{~h}$ ) and analyzed for CHOP mRNA levels. (b and c) Naïve EA.hy cells were treated with PEG-SOD $(100 \mathrm{U} / \mathrm{ml})$ or NAC $(10 \mathrm{mM})$ for $24 \mathrm{~h}$ before addition of tunicamycin and quantification of CHOP mRNA (b) or protein (c). (d) Naive or PON2-GFP overexpressing cells were tunicamycin-stimulated (1 $\mu \mathrm{g} / \mathrm{ml}$; $30 \mathrm{~min}$ ) and analyzed for JNK-phosphorylation (fold increase shown below). GAPDH protein levels served as loading control. Similar results were obtained for other time points and in multiple experiments. (e) Indicated cells were treated with tunicamycin $(1 \mu \mathrm{g} / \mathrm{ml} ; 8 \mathrm{~h})$ or JNK inhibitor SP600125 (10 $\mu \mathrm{M})$ or both, followed by CHOP mRNA quantification. (f) Named cells treated with scrambled (Ctrl) or JNK-specific siRNA were stimulated with tunicamycin ( $1 \mu \mathrm{g} / \mathrm{ml} ; 8 \mathrm{~h})$, followed by CHOP mRNA quantification. Symbols represent mean \pm S.E.M. $n=3-9 ;$ n.s. $=$ not significant; ${ }^{\star} P<0.05 ;{ }^{* \star} P<0.01 ;{ }^{\star \star \star} P<0.001$

caspase signaling. As expected, activation of caspases 8, 9 , and 3 in response to these treatments was significantly lower in PON2-overexpressing cells (Figure 6b).

Confocal microscopy of live cells revealed that PON2 signals overlapped with both ER and mitochondria (Supplementary Figure S2), which confirms previous biochemical approaches and also more recent data reporting individual

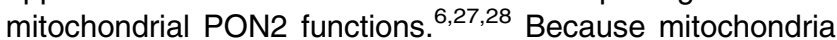
can be crucial to apoptosis and upstream of caspases, we applied a FACS-based approach to test whether PON2 affected cytochrome $c$ release. Staurosporine induced a dose-dependent increase in mitochondrial cytochrome $c$ liberation in naive cells (Figure 7a, left). This was substantially diminished in cells overexpressing PON2 (Figure 7a, right), which explains the reduced apoptosis rates described above. To address whether PON2 has direct mitochondrial functions or affects cytoplasmic caspase feedback loops, staurosporine-induced cytochrome $c$ release was assessed in the presence of pan-caspase inhibitor, Z-VAD-fmk. This blocked caspases 8,9 , and $3 / 7$, but did not prevent cytochrome $c$ release (Supplementary Figure S3), suggesting that PON2 functions at the mitochondria.

We next analyzed peroxidation of cardiolipin, a lipid at the inner mitochondrial membrane that critically controls cytochrome $c$ release ${ }^{31}$ Staurosporine dose-dependently caused cardiolipin peroxidation in naive cells, whereas PON2-overexpressing cells were substantially more resistant (Figure 7b). Cardiolipin peroxidation is preceded by excess mitochondrial $\mathrm{O}_{2}^{-}$generation. We finally demonstrate that PON2 counteracts such event: Cells with or without stable PON2-HA overexpression were labeled with Mito-HE (mitochondriatargeted dihydroethidium), treated with complex III-inhibitor antimycin $\mathrm{A}$ to induce $\mathrm{O}_{2}^{-}$, and analyzed by a fluorometer or FACS at wavelengths specific for $\mathrm{O}_{2}^{-}$-induced Mito-HE products. The pronounced accumulation of mitochondrial $\mathrm{O}_{2}^{-}$observed in naive cells was significantly lower in 
a
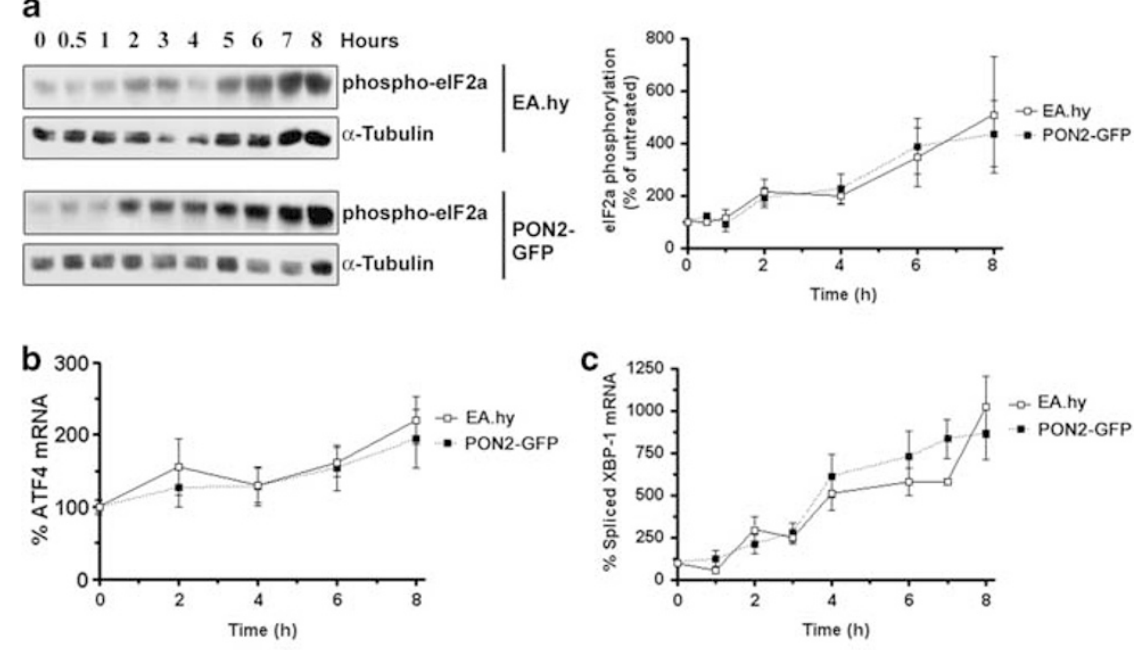

d

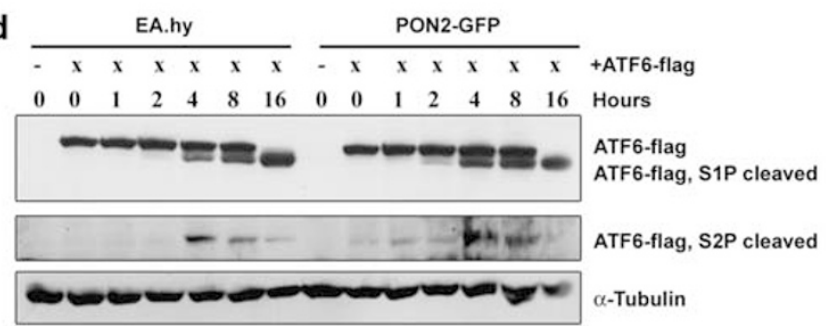

Figure 4 No alteration of classical ER stress-transducers by PON2. (a) Naive or PON2-GFP overexpressing cells were treated with tunicamycin followed by analysis of elF2a Ser ${ }^{51}$-phosphorylation and $\alpha$-tubulin. One representative blot is shown (left); six independent experiments were quantified (right). (b and $\mathbf{c}$ ) Similar to A, but analyzing mRNA levels of ATF4 (c) or spliced XBP1 (d). (d) Named cells were transfected with ATF6-flag plasmid, treated with tunicamycin and analyzed for ATF6-flag and $\alpha$-tubulin. Symbols represent mean \pm SEM; $n=3-12$ : no significant differences were detected

PON2-overexpressing cells (Figure 7c and Supplementary Figure S4A). Similarly, antimycin-treated mitochondria isolated from PON2-HA-overexpressing cells produced less $\mathrm{O}_{2}^{-}$ than those from controls (Supplementary Figure S4B). Two contemporary analyses revealed that PON2 prevents $\mathrm{O}_{2}^{-}$ production because of an interaction with coenzyme Q10. ${ }^{27,28}$ Also, PON2 wildtype and lactonase-deficient mutants were equally protective against intrinsic apoptosis. ${ }^{27}$ Thus, PON2 diminishes pro-apoptotic mitochondrial $\mathrm{O}_{2}^{-}$bursts that prevent cardiolipin peroxidation, cytochrome $c$ release, caspase activation, and cell death.

PON2 does not impact on extrinsic apoptotic pathways. In contrast to intrinsic apoptosis, PON2 failed to attenuate extrinsic signaling. This is demonstrated by the fact that PON2 did not alter any level of signal transmission in response to death receptor-dependent apoptosis by TRAIL, as documented by activation of caspase- 8 after $2 \mathrm{~h}$, caspase-3 after $6 \mathrm{~h}$ and cell death after $16 \mathrm{~h}$ (Figures 8a-c, respectively). PON2 also did not decrease caspase-3 activation in response to TNF $\alpha /$ actinomycin $\mathrm{D}$ co-treatment (Figure 8d). Hence, PON2 is ineffective when ligandmediated stimuli are sufficiently strong to activate caspasecascades at the receptor complex (type-I cells). A schematic summary of PON2's anti-apoptotic function is depicted in Supplementary Figure S5.

\section{Discussion}

Treatment of malignancies is often hampered because tumor cells modulate execution of the cell death program to promote apoptosis resistance, which contributes to failure of immunosurveillance and therapeutic approaches. This can be achieved by potentiation of anti-apoptotic or attenuation of pro-apoptotic signaling. The mechanistic insight provided in this study and the result that several tumors overexpress PON2, combined with the finding that PON2 deficiency destabilizes tumor cells, led us to propose PON2 as novel putative anti-tumor target.

PON2 overexpression significantly protected cells from oxidative stress and, more importantly, from ER stressinduced apoptosis. ${ }^{6,26}$ It was totally unsolved, however, how the diminished caspase activation was achieved and whether this was limited to ER stress. We here revealed that PON2 overexpression diminished the induction of pro-apoptotic $\mathrm{CHOP}$. Further, we provide evidence that $\mathrm{CHOP}$ deficiency prevents cardiolipin peroxidation, loss of mitochondrial membrane potential, nuclear condensation and caspase activation in response to ER stress. Given these results and many other reports that demonstrate the fundamental role of $\mathrm{CHOP}, 3,4,32$ it is clear that reduced CHOP levels, as resembled by PON2 overexpression, contribute to cell survival. One thus may speculate whether the known antiatherogenic potential of PON2 ${ }^{18,33}$ results from its effect on $\mathrm{CHOP}$, when considering its linkage to atherosclerosis. ${ }^{34}$ 

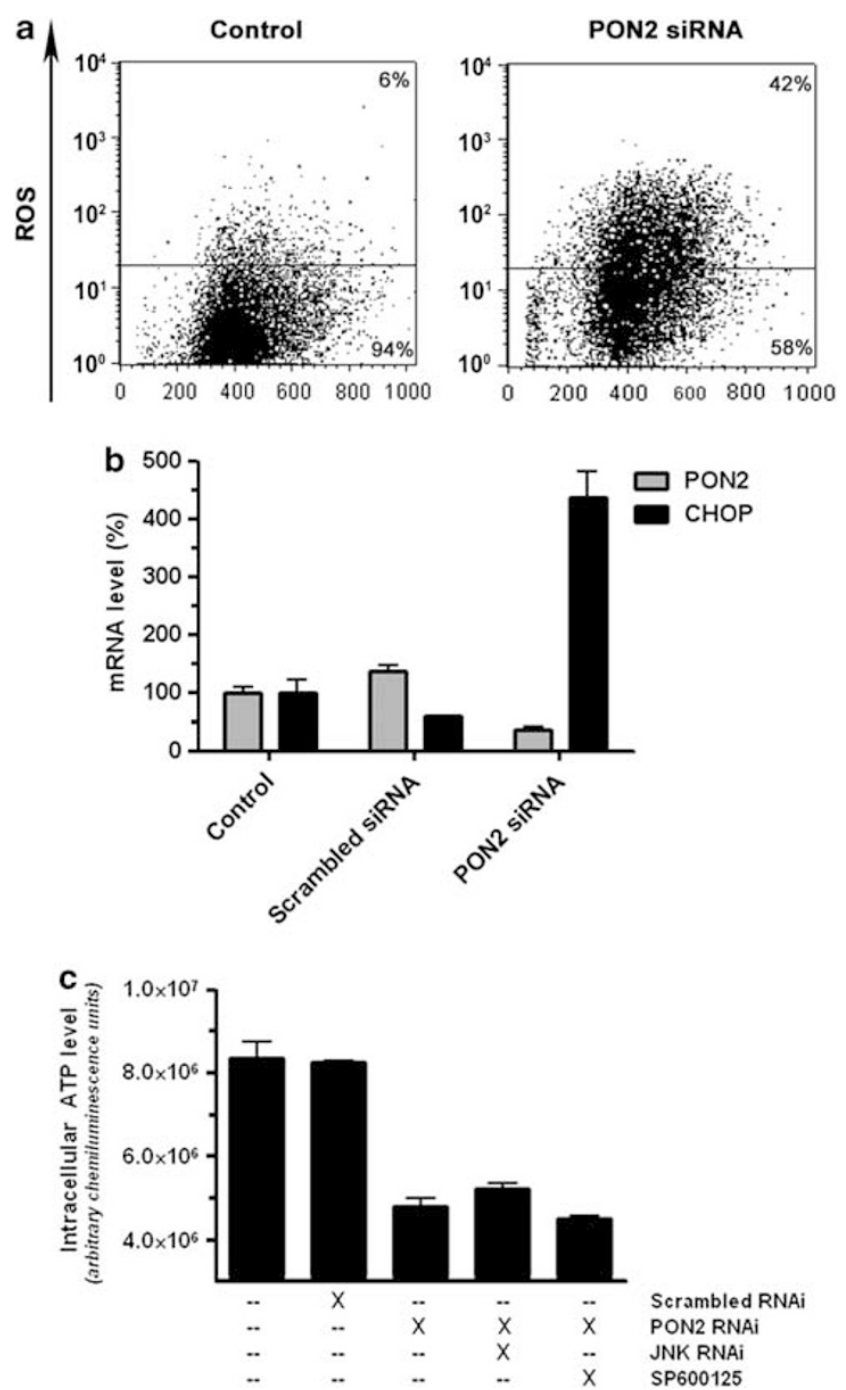

Figure 5 PON2 knock-down induces ROS production and CHOP expression, but viability loss does not depend on JNK signaling. (a) A549 cells were left untreated (control) or were treated with PON2 siRNA for 2 days, stained for intracellular oxidative stress with $\mathrm{H}_{2}$-DCFDA and analyzed by FACS. Scrambled siRNA behaved as control (not shown). Cells above threshold line are considered ROS positive. (b) A549 cells were left untreated or were treated with scrambled or PON2 siRNA for 3 days and analyzed for CHOP and PON2 mRNA expression. (c) A549 cells were left untreated or were treated for 2 days with scrambled, PON2, or JNK specific siRNAs, or SP600125 $(10 \mu \mathrm{M})$, or combinations thereof, followed by determination of intracellular ATP levels

The UPR IRE $1 \alpha$ branch is of particular importance, as it produces the spliced-XBP1 transcription factor and the IRE1/ TRAF2/ASK1 signaling cascade, which both activates JNK and induces $\mathrm{CHOP} .{ }^{35,36}$ Moreover, $\mathrm{CHOP}$ induction results from oxidative stress, which accompanies ER stress ${ }^{29,37}$ and appears upstream of XBP1 and/or JNK ${ }^{30}$ Most likely owing to its anti-oxidative role during ER stress, ${ }^{6}$ PON2 reduces JNK activation and $\mathrm{CHOP}$ induction. Likewise, other studies revealed a reduced $\mathrm{CHOP}$ induction by anti-oxidative interventions. $^{3,29}$ It remains undetermined what particular redoxsensitive pathway is altered by PON2 to reduce JNK phosphorylation, because this is beyond our scope and requires intense investigation in an entirely new though interesting project. It is a matter of debate that ROS sources are activated during ER stress and it is presently unknown whether PON2 reduces ROS only at the mitochondria, or perhaps also at the ER, or in conjunction, for example, with NADPH oxidases (as shown for NOX4 in TGF- $\beta$ stimulated smooth muscle cells. ${ }^{6}$ ) Similarly, multiple pathways link ROS with JNK activation, such as ASK1 (modulated by thioredoxin, glutaredoxin, PKD, or 14-3-3/PP5), Src kinase, Glutathione S-transferase $\mathrm{Pi}$, RIP/TRAF2, or IRE1/TRAF2/ASK1. ${ }^{30}$ Therefore, a future challenge is to investigate these pathways and the relatedness to PON2 and to locate the precise generation of ROS. More straightforward, however, it is established that PON2 prevents the generation of mitochondrial superoxide, ${ }^{27,28}$ which controls subsequent apoptotic pathways similar to cardiolipin peroxidation and cytochrome $c$ release.

Conceptual advance comes from our finding that PON2 modulates execution of the cell death program directly at the mitochondria, thereby allowing modification of several apoptotic pathways converging at these organelles. In this manner, we provide evidence for the first time that PON2's effect is not limited to ER stress hence, it may be an interesting pharmacological target, be it to prevent either cell loss or apoptotic escape. Because PON2 amplifies an already existing reaction, it may not be confounded by targeting problems. Moreover, diminished apoptotic signaling is accomplished at an early step, that is, before a 'point-of-noreturn' has been passed due to cardiolipin peroxidation and subsequent cytochrome $c$ release. Large-scale analyses must address which specific tumors upregulate PON2, whether this is subtype and/or stage-specific and what pathways are involved. A simple explanation is that chromosome-7, which harbors the PON cluster, is amplified in several tumors, such as papillary renal kidney carcinoma cells or prostate adenocarcinomas. The urokinase plasminogen activator system may also be relevant, as this is increased in numerous cancers and upregulates PON2. ${ }^{38}$ Given that high basal PON2 levels did not correlate with high sensitivity to its knock-down, future studies should test larger tumor cell panels for PON2 deficiency-simulated cell death.

Our study revealed lacking protection by PON2 against receptor-triggered signaling. Upon ligand binding, the receptor recruits the Fas-associated death domain protein FADD, thereby forms the death-inducing signaling complex, which activates, for example, caspase-8. Because this sufficiently activates several other caspases, execution of apoptosis is unaltered, for example, by mitochondrial acting $\mathrm{Bcl}-2$ proteins in so-called type-I cells; however, some receptor-triggered pathways also employ mitochondrial amplifier feed-back loops via Bid cleavage in type-Il cells, which led to the proposal of two distinct but overlapping routes to cell death. ${ }^{39}$ In agreement, PON2 altered caspase-8 activation in response to staurosporine and actinomycin but not TRAIL. The fact that PON2 did not alter ligand-induced caspase activation or cell death argues against a role on receptor-triggered apoptosis in type-I cells.

Several studies demonstrated that PON2 deficiency predisposes to vascular complications and atherosclerosis. ${ }^{11,18}$ Likewise, PON2 may impact on diabetes, given the importance of ER stress, JNK signaling and CHOP expression for 
a
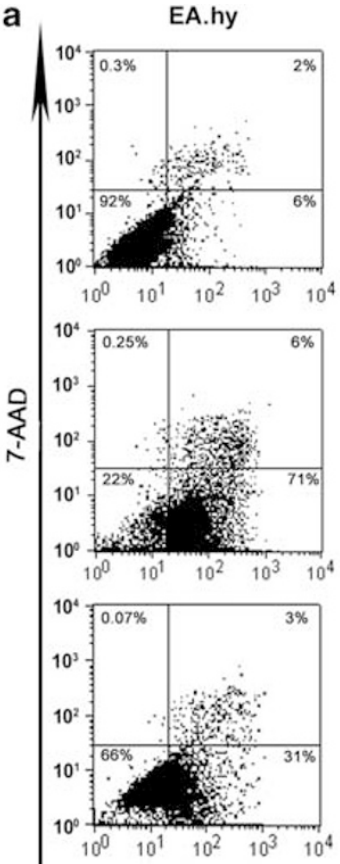

PON2-HA

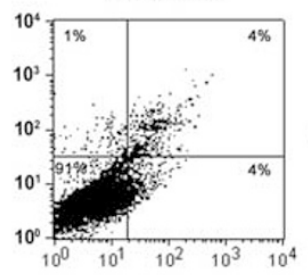

Untreated

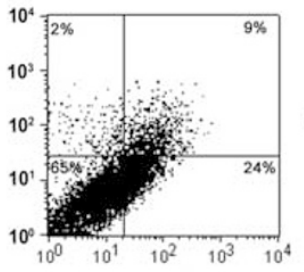

Staurosporine

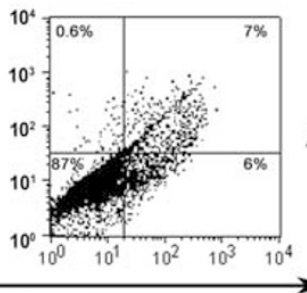

Actinomycin

Annexin $\mathrm{V} P E$
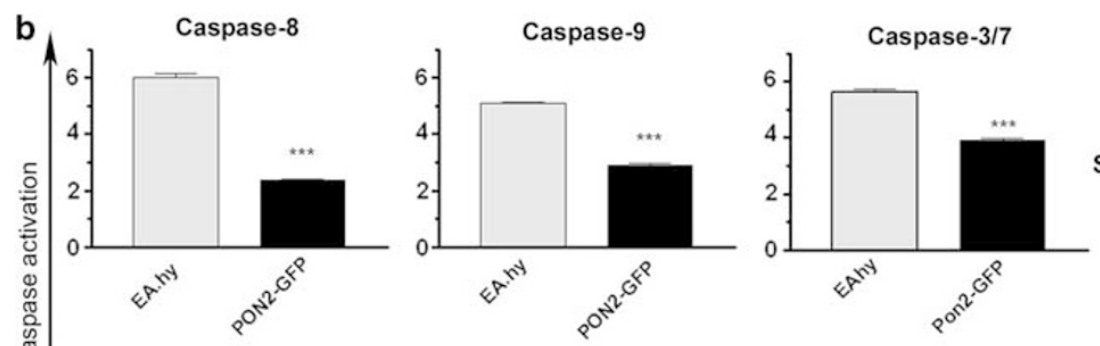

Staurosporine
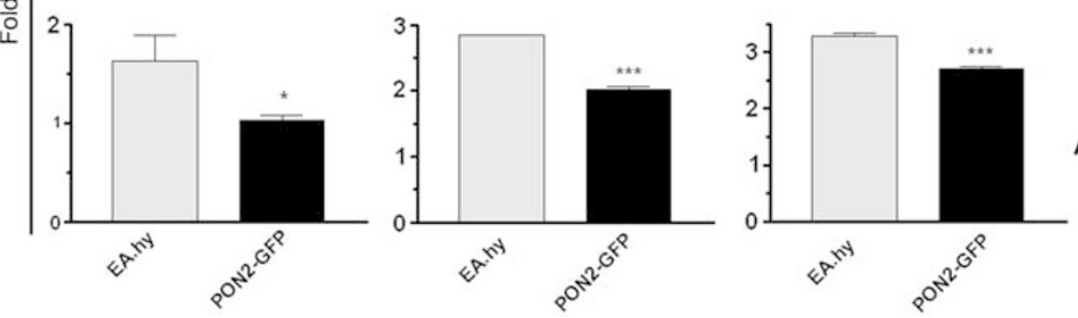

Actinomycin D

Figure 6 PON2 overexpression reduces intrinsic pro-apoptotic stimulation. (a) Naive or PON2-HA-overexpressing cells were left untreated or were treated with staurosporine $(0.5 \mu \mathrm{M} ; 16 \mathrm{~h})$ or actinomycin $\mathrm{D}(5 \mu \mathrm{g} / \mathrm{ml} ; 24 \mathrm{~h})$ and examined by flow cytometry. Comparable results were obtained for other concentrations of staurosporine $(0.1-1 \mu \mathrm{M})$ or actinomycin $\mathrm{D}(0.5-10 \mu \mathrm{g} / \mathrm{ml})$. (b) Indicated cells were treated for $24 \mathrm{~h}$ with staurosporine $(1 \mu \mathrm{M})$ or actinomycin $\mathrm{D}(1 \mu \mathrm{g} / \mathrm{ml})$ and assessed for activation of caspases 8,9 , and $3 / 7$. ${ }^{*} P<0.05 ;{ }^{* * *} P<0.001$

$\beta$-cell homeostasis. ${ }^{4}$ From such perspective, enhanced PON2 expression may be desirable. However, our results disclose that PON2 upregulation could be detrimental by supporting apoptosis escape and tumor development. Therefore, the pharmacological downregulation of PON2 in specific tumors may one day add to established cancer therapies.

\section{Materials and Methods}

Cell culture, plasmids, and material. Human endothelial EA hy 926 cells were cultured in Dulbecco's modified Eagle's medium without Phenol Red (Sigma, St. Louis, MO, USA) containing sodium pyruvate (PAA Laboratories, Pasching, Austria), antibiotics penicillin/streptomycin, hypoxanthine/aminopterin/thymidine supplement, GlutaMAX (Invitrogen, Carlsbad, CA, USA) and 10\% (v/v) fetal calf serum (Perbio, Thermo Fisher Scientific, Waltham, MA, USA). Stable cell lines, plasmids and transfection procedures were described before. ${ }^{6,26}$ HEK293, Jurkat, K562, and A549 cells were from the German Collection of Microorganisms and Cell Cultures. K562 and Jurkat cells were cultured in RPMI with phenol red (Sigma), $10 \%$ fetal calf serum, sodium-pyruvate, and penicillin / streptomycin. A549 received the same medium as EA.hy 926 , but $5 \%$ serum. Cells were cultured at $37^{\circ} \mathrm{C}$ in a humidified atmosphere under $5 \% \mathrm{CO}_{2}(10 \%$ for EA.hy 926$)$.

Staurosporine, tunicamycin, actinomycin D, antimycin A, polyethylene glycol (PEG)conjugated SOD (PEG-SOD), doxorubicin, N-acetyl-cysteine, imatinib, and SP600125 were purchased from Sigma; Mito-HE was from Molecular Probes (Invitrogen / Life Technologies); TRAIL and TNF $\alpha$ were from Miltenyi Biotech. Plasmid p3xFLAG-ATF6 was cloned by R Prywes ${ }^{40}$ and is distributed as Addgene plasmid 11975 (Addgene). 

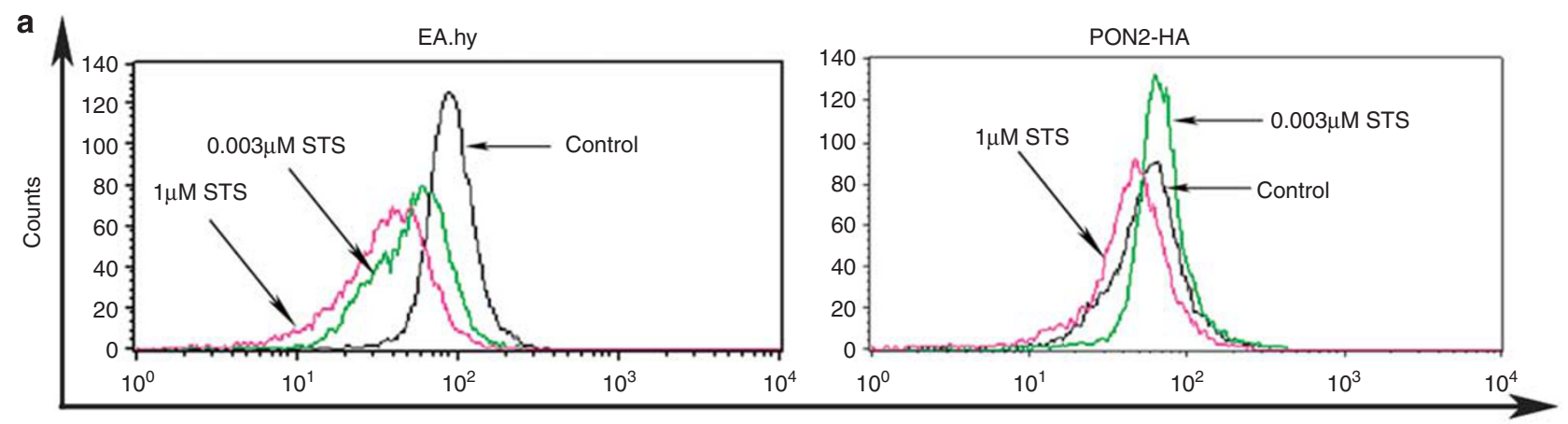

Cytochrome C

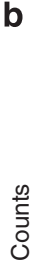

on

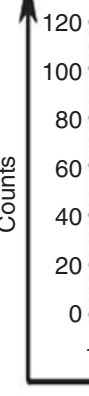

EA.hy

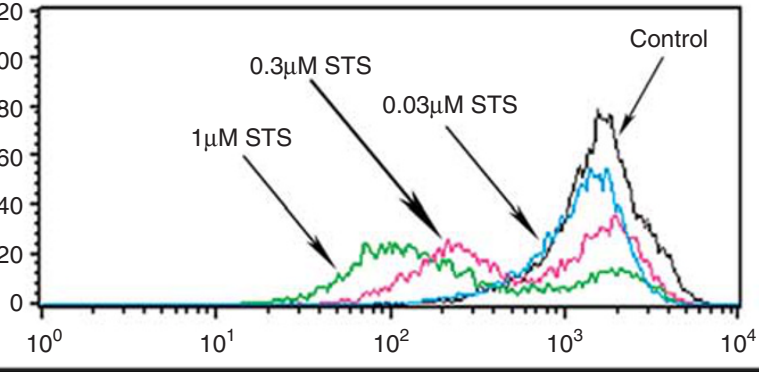

PON2-HA

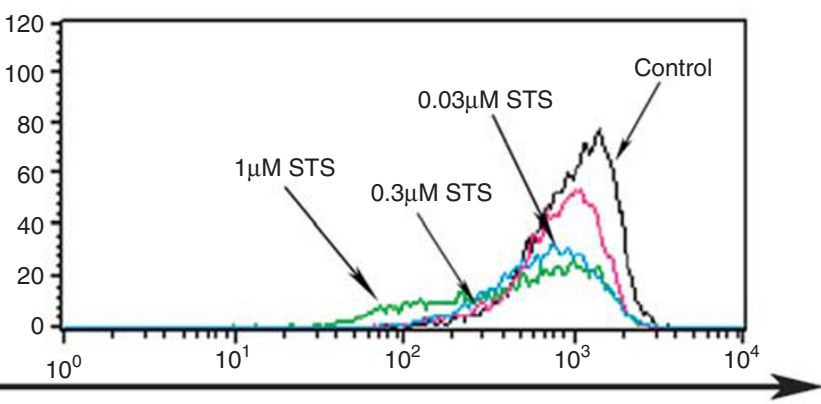

NAO (Cardiolipin)

c

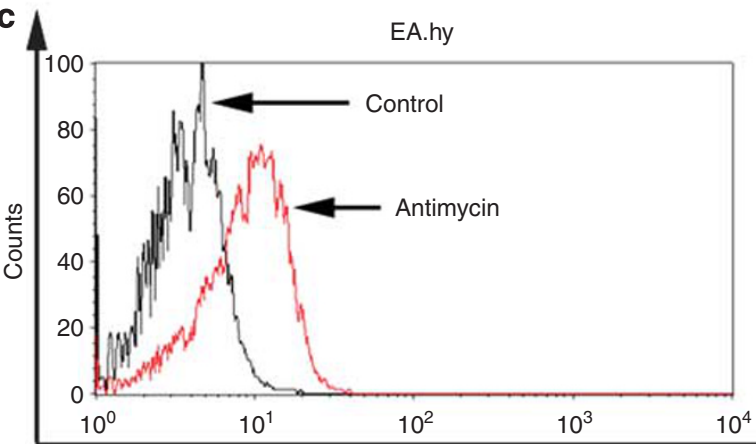

PON2-HA

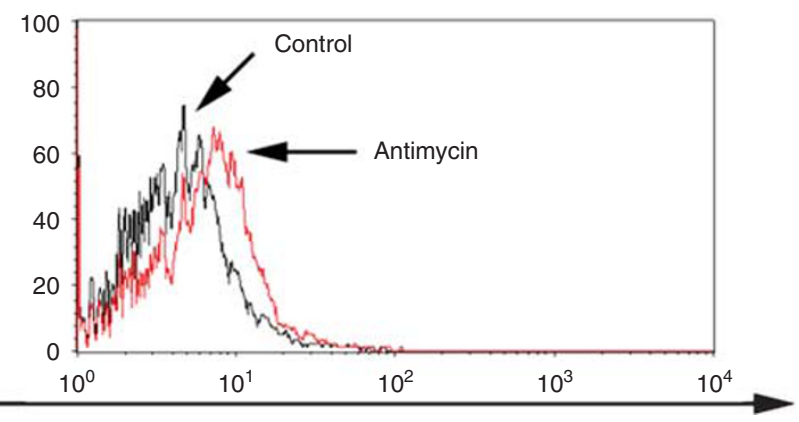

Mito-HE fluorescence (mitochondria $\mathrm{O}_{2}^{-}$)

Figure 7 PON2 diminishes cytochrome $c$ release, cardiolipin peroxidation and mitochondrial $\mathrm{O}_{2}^{-}$levels. (a) Indicated cells were stimulated with staurosporine (STS) for $16 \mathrm{~h}$ and FACS analyzed for mitochondrial cytochrome $c$. A left shift of the peak indicates cytochrome $c$ liberation. (b) Similar experiment as in (b). Cells were assessed for cardiolipin peroxidation by NAO staining. A left shift of the peak indicates enhanced cardiolipin peroxidation. (c) Named cells were loaded with Mito-HE and treated with antimycin (15 $\mu \mathrm{M} ; 2 \mathrm{~h}) . \mathrm{O}_{2}^{-}$-specific mitochondrial 2-HE was determined FACS. A right shift of the peak reflects mitochondrial superoxide production

Fractionation and western blotting. Unless otherwise indicated, tunicamycin was used with $1 \mu \mathrm{g} / \mathrm{ml}$ for $6 \mathrm{~h}$; controls contained $0.5 \%$. solvent (DMSO). To monitor ATF6 processing, cells grown in six wells were transfected with $0.25 \mu \mathrm{g}$ p3xFLAG-ATF6 plus $1.5 \mu \mathrm{g}$ pCDNA3 using Nanofectin (PAA). The low amount of FLAG-ATF6 ensured tight ER stress regulation. Mitochondria were isolated according to recently published procedures. ${ }^{27}$ Preparation of total protein lysates, SDS-PAGE, and western blotting using a semi-dry transfer system (Bio-Rad, Hercules, CA, USA) was performed as before. ${ }^{6,26}$ When phospho-antibodies were used, lysates contained Phospho-STOP (Roche, Basel, Switzerland). For analysis of CHOP and mitochondrial fractions, we performed tankblots using Bio-Rad's Mini-Trans-Blot-System and PVDF membranes (Amersham, Chalfont St Giles, Great Britain, Hybond-P). Protein content was determined using the bicinchoninic acid protein assay reagent (Pierce, Thermo Fisher Scientific). Immunodetected proteins were visualized by Western-Lightning chemiluminescence kit (Perkin Elmer, Waltham, MA, USA) using X-ray film exposure and were quantitatively evaluated with a ChemiDoc XRS imaging system (Bio-Rad) equipped with QuantityOne 4.6.7 software. All samples were quantitatively normalized to $\alpha$-tubulin, glycerinaldehyde-3-phosphate-dehydrogenase (GAPDH) and/or p38-MAPK.
Antibodies. We used the following antibodies: rabbit-anti-phospho-elF2a (Ser51), rabbit-anti-p38-MAPK, rabbit-anti-phospho-SAPK/JNK (Thr183; Tyr185) (Cell Signaling Technology, Danvers, MA, USA); rabbit-anti-ATF4, mouseanti-GAPDH 6C5, rabbit-anti-CHOP F168, goat-anti-Lamin C-20 (Santa Cruz, Santa Cruz, CA, USA); mouse-anti-Flag M2 (Stratagene, Agilent Technologies, Santa Clara, CA, USA); mouse-anti-Complex III subunit core 2 (MitoSciences, Eugene, OR, USA); mouse-anti-Cytochrome $c$ clone $7 \mathrm{H} 8.2 \mathrm{C} 12$. (BD Biosciences, Franklin Lakes, NJ, USA); rabbit-anti-PON2 ${ }^{6}$ mouse- $\alpha$-Tubulin Ab2 (Dianova, Hamburg, Germany); mouse-anti-hemagglutinin HA-7 (Sigma); HRP-conjugated secondary antibodies were from Sigma and Cell Signaling Technology.

qRT-PCR. RNA was isolated with PeqGold RNA isolation kits from Peqlab. $80 \mathrm{ng}$ of RNA was ued for cDNA generation using High Capacity CDNA Reverse Transcription kit (Applied Biosystems, Life Technologies, Carlsbad, CA, USA). RNA expression levels were quantitatively analyzed using $2 \mu \mathrm{l}$ cDNA, 0.1 unit Go-Taq polymerase (Promega, Madison, WI, USA), $0.4 \mu 110 \mathrm{mM}$ dNTPs and 

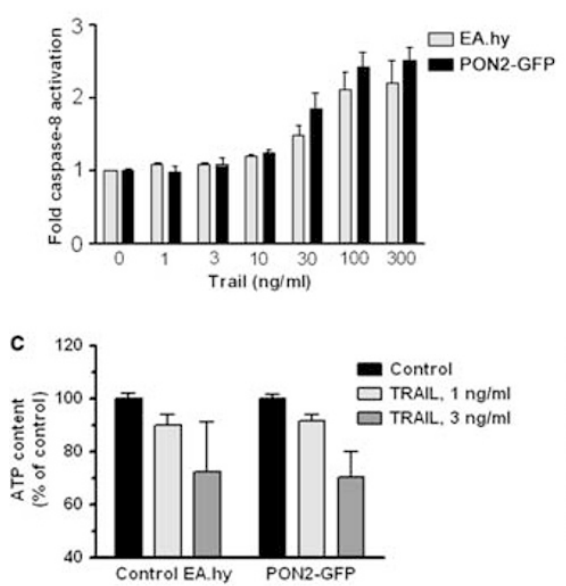

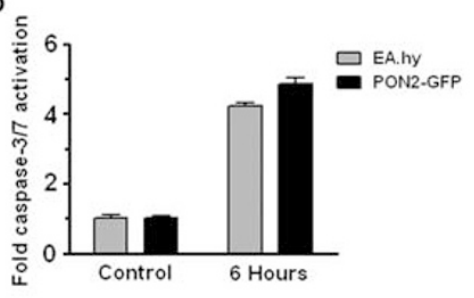

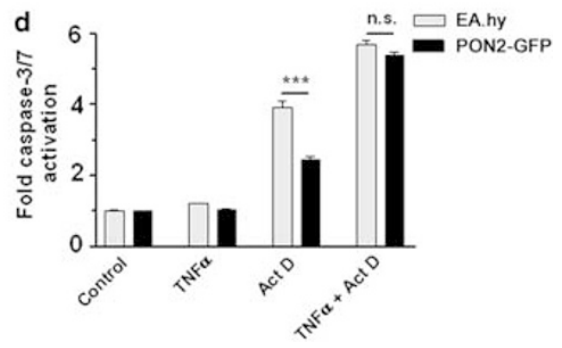

Figure 8 PON2 does not alter ligand-induced caspase activation. Naive or PON2-GFP overexpressing cells were treated with various concentrations of TRAIL and analyzed for caspase-8 activity after $2 \mathrm{~h}(\mathbf{a})$, or with $100 \mathrm{ng} / \mathrm{ml}$ TRAIL and analyzed for caspase- $3 / 7$ activity after $6 \mathrm{~h}(\mathbf{b})$, or 1 or $3 \mathrm{ng} / \mathrm{ml}$ TRAlL followed by determination of intracellular ATP levels after $16 \mathrm{~h}$ (c). We used low TRAIL doses in C, as higher concentrations killed cells too rapidly such that an overwhelming stimulus could have masked potential effects of PON2. (d) Named cells were treated for $16 \mathrm{~h}$ with TNF- $\alpha(10 \mathrm{ng} / \mathrm{ml})$ or actinomycin D $(1 \mu \mathrm{g} / \mathrm{ml})$ or both; subsequently, caspase-3/7 activity was assessed. Symbols represent mean \pm S.E.M. $n=3-6$ independent experiments (>duplicates each); n.s. $=$ not significant; ${ }^{* * *} P<0.001$

$20 \mathrm{pmol}$ per primer per $20 \mu \mathrm{l}$ reaction in a Bio-Rad Laboratories iCycler. The following Taqman primers (Eurofins MWG Operon) were used: GAPDH: sense 5'-CAACAGCCTCAAGATCATCAGC-3'; antisense $5^{\prime}$-TGGCATGGACTGTGGTCA TGAG-3'; probe 5'-CCTGGCCAAGGTCATCCATGACAAC-3'; CHOP: sense $5^{\prime}$-GA CCTGCAAGAGGTCCTGTC-3'; antisense $5^{\prime}$-CTCCTCCTCAGTCAGCCAAG-3'; probe $5^{\prime}$-CACCACTCTTGACCCTGCTT-3'; spliced-XBP1: sense $5^{\prime}$-GGAGTTAA GACAGCGCTTGG-3'; antisense 5'-GCACCTGCTGCGGACTC-3'; probe 5'-GAA GCCAAGGGGAATGAAGT-3'; PON2: sense $5^{\prime}$-TCGTGTATGACCCGAACAAT CC-3'; antisense 5'-AACTGTAGTCACTGTAGGCTTCTC-3'; probe 5'-TCGTCAG AGGTTCTCCGCATCCAGA-3'; JNK1: sense $5^{\prime}$-CCACCAAAGATCCCTGACAAG$3^{\prime}$; antisense $5^{\prime}$-TGGATGCTGAGAGCCATTG-3'; probe $5^{\prime}$-ACGGGGGCAGCCCT CTCCTTTAG- $3^{\prime}$. Predesigned primers for ATF4 detection were from Applied Biosystems.

Detection of mitochondrial superoxide, membrane potential $(\Delta \Psi M)$ and oxidative stress. Assessment of mitochondrial superoxide was recently described. ${ }^{27}$ To monitor $\Delta \Psi \mathrm{M}$, cells seeded in Lab-Tek chamber slides (Nunc) were treated as indicated, washed with HBSS, stained with $25 \mathrm{nM}$ $\mathrm{DiOC}_{6}$ (Molecular Probes) and Draq5 (Cell Signaling Technology) for $20 \mathrm{~min}$ at $37^{\circ} \mathrm{C}$, washed, suspended in growth medium and analyzed by confocal microscopy (see above) under constant conditions (i.e., laser power, gain, pixel dwell etc.). To detect oxidative stress, cells were treated with siRNA (see below), incubated for 2 to 3 days, washed with HBSS, labeled with $2.5 \mathrm{nM} \mathrm{cm}-\mathrm{H}_{2}$ DCFDA (Molecular Probes; $30 \mathrm{~min} ; 37^{\circ} \mathrm{C}$ ), washed, detached, washed, suspended in HBSS, and analyzed by flow cytometry (see below; FITC filter set).

Detection of mitochondrial cytochrome $c$ release. Cells grown in 12-well dishes were trypsinized, resuspended in growth medium, pelleted $(350 \times \mathrm{g}$, $4^{\circ} \mathrm{C}, 5 \mathrm{~min}$ ), washed with chilled PBS and re-centrifuged, washed twice in chilled wash buffer (PBS, $1 \%$ FCS, $0.1 \%$. Na-Azide), re-centrifuged and fixed in $4 \%$ paraformaldehyde (in PBS; $20 \mathrm{~min} ; 4^{\circ} \mathrm{C}$ ). Fixed cells were washed again, centrifuged, and permeabilized/blocked with PBS containing $0.2 \%$ saponin (Fluka, Sigma Aldrich, St. Louis, MO, USA) and mouse-lgG1 $\kappa$ (MOPC-21; Sigma; 1:10) for $5 \mathrm{~min}$ at RT. After washing and centrifugation, cells were incubated with mouse-anticytochrome $c$ (clone 7H8.2C12; BD Biosciences; $1: 20$ in PBS; $20 \mathrm{~min} ; 4^{\circ} \mathrm{C}$ ), washed and centrifuged, incubated with secondary antibody (AlexaFluor-647 goat antimouse $\operatorname{lgG}_{2 b}$; Molecular Probes; 1:40 in PBS; $20 \mathrm{~min} ; 4^{\circ} \mathrm{C}$ ), washed twice, and finally resuspended in $100 \mu \mathrm{l}$ \% PFA, followed by addition of $400 \mu \mathrm{l}$ of ice-cold PBS and immediate FACS analysis.
Cardiolipin peroxidation. Cardiolipin was measured by incubating cells with acridine orange 10-N-nonyl bromide (NAO; Invitrogen; $50 \mathrm{nM} ; 30 \mathrm{~min} ; 37^{\circ} \mathrm{C}$ ), which only binds non-peroxidized cardiolipin. Then, cells were trypsinized, resuspended in complete growth medium, pelleted $\left(350 \times g, 4^{\circ} \mathrm{C}, 5 \mathrm{~min}\right)$, washed with PBS, re-centrifuged, fixed in $2 \%$ paraformaldehyde and analyzed by FACS. Alternatively, cells grown in 96 -well plates were stained with NAO as before and analyzed by a Fluostar-Optima fluometer.

ATP content and caspase activity. To investigate intracellular ATP content, cells were seeded in opaque 96-well plates and treated next day with the indicated stimulus and duration. Then, the CellTiterGlo reagent (Promega) was used as recommended by the supplier. Alternatively, we used Caspase-Glo assays (Promega) according to the manufacturer's protocol and previously published data acquisition. ${ }^{6}$

RNA interference. Cells at $60 \%$ confluency were transfected with $50 \mathrm{nM}$ PON2-specific siRNA (5'-TTAGTATTCCTCCAGGCTTATCTGG-3'; Invitrogen), $35 \mathrm{nM}$ CHOP or JNK-specific smart-pool siRNAs (a mix of four different siRNAs each; Dharmacon, Thermo Fisher Scientific) or scrambled siRNA (Invitrogen) using Saint-Red reagent (Synvolux, Groningen, Netherlands).

Flow cytometry. Cells were stained with annexin-V-phycoerythrin and 7-amino-actinomycin (apoptosis-detection-kit-l; BD Biosciences) as recommend by the manufacturer; 10000 fluorescent events were acquired using a Facs-Calibur equipped with CellQuest Pro software (BD Biosciences).

Cancer survey panels. PON2 expression levels were determined in cancer versus normal tissues by quantitative real-time PCR using TissueScan Cancer Survey Panel-III ( $4 \times 96$-well format) and Lymphoma Cancer Panel-II (Origene). Pre-normalized (beta-actin) cDNAs were solubilized (15 min on ice) in a $20 \mu \mathrm{l}$ reaction mix consisting of $10 \mathrm{pmol}$ per primer (see above) and the JumpStart Taq polymerase mix from Sigma. PON2 cDNA levels were quantified and normalized to those of GAPDH. See supplier's homepage (http://www.origene.com/qPCR/TissueqPCR-Arrays.aspx) for details on the tissues and comprehensive pathology reports. Real-time GPCR was performed in a Bio-Rad Laboratories iCycler. In order to address PON2 protein mass in cancer samples, pooled tumor, or normal tissue western blots were purchased from Assay Depot; PON2 was normalized to both GAPDH and p38-MAPK. 
Software, statistics and image acquisition. GraphPad Prism- 5 was used for calculations, non-linear regression curve fitting or statistical evaluation using 1-/2-way ANOVA with Bonferroni's multiple comparisons post test (see Figure legends). $P<0.05$ was considered significant. Adobe Photoshop software was used for image acquisition. If necessary, only brightness and/or contrast were changed simultaneously for all areas of any blot.

\section{Conflict of interest}

The authors declare no conflict of interest.

Acknowledgements. We thank Ute Gödtel-Armbrust and Hartmut Kleinert for providing doxorubicin, caspase inhibitors and SP600125. Financial support (to SH) came from the University Medical Center Mainz and the German Research Foundation (DFG-grant HO3925/4-1).

1. Zhang K, Kaufman RJ. The unfolded protein response: a stress signaling pathway critical for health and disease. Neurology 2006; 66 (2 Suppl 1): S102-S109.

2. Ma Y, Hendershot LM. The role of the unfolded protein response in tumour development: friend or foe? Nat Rev Cancer 2004; 4: 966-977.

3. Oyadomari S, Mori M. Roles of CHOP/GADD153 in endoplasmic reticulum stress. Cell Death Differ 2004; 11: 381-389.

4. Song B, Scheuner D, Ron D, Pennathur S, Kaufman RJ. Chop deletion reduces oxidative stress, improves beta cell function, and promotes cell survival in multiple mouse models of diabetes. J Clin Invest 2008; 118: 3378-3389.

5. Ott M, Gogvadze V, Orrenius S, Zhivotovsky B. Mitochondria, oxidative stress and cell death. Apoptosis 2007; 12: 913-922.

6. Horke S, Witte I, Wilgenbus P, Kruger M, Strand D, Forstermann U. Paraoxonase-2 reduces oxidative stress in vascular cells and decreases endoplasmic reticulum stressinduced caspase activation. Circulation 2007; 115: 2055-2064.

7. $\mathrm{Ng} \mathrm{CJ}$, Wadleigh DJ, Gangopadhyay A, Hama S, Grijalva VR, Navab M et al. Paraoxonase-2 is a ubiquitously expressed protein with antioxidant properties and is capable of preventing cell-mediated oxidative modification of low density lipoprotein. J Biol Chem 2001; 276: 44444-44449.

8. Rothem L, Hartman C, Dahan A, Lachter J, Eliakim R, Shamir R. Paraoxonases are associated with intestinal inflammatory diseases and intracellularly localized to the endoplasmic reticulum. Free Radic Biol Med 2007; 43: 730-739.

9. Draganov DI, Teiber JF, Speelman A, Osawa Y, Sunahara R, La Du BN. Human paraoxonases (PON1, PON2, and PON3) are lactonases with overlapping and distinct substrate specificities. J Lipid Res 2005; 46: 1239-1247.

10. Teiber JF, Billecke SS, La Du BN, Draganov DI. Estrogen esters as substrates for human paraoxonases. Arch Biochem Biophys 2007; 461: 24-29.

11. Camps J, Marsillach J, Joven J. The paraoxonases: role in human diseases and methodological difficulties in measurement. Crit Rev Clin Lab Sci 2009; 46: 83-106.

12. Stoltz DA, Ozer EA, Ng CJ, Yu JM, Reddy ST, Lusis AJ et al. Paraoxonase-2 deficiency enhances Pseudomonas aeruginosa quorum sensing in murine tracheal epithelia. $A m \mathrm{~J}$ Physiol Lung Cell Mol Physiol 2007; 292: L852-L860.

13. Teiber JF, Horke S, Haines DC, Chowdhary PK, Xiao J, Kramer GL et al. Dominant role of paraoxonases in inactivation of the Pseudomonas aeruginosa quorum-sensing signal N-(3oxododecanoyl)-L-homoserine lactone. Infect Immun 2008; 76: 2512-2519.

14. Horke S, Witte I, Altenhofer S, Wilgenbus $P$, Goldeck M, Forstermann U et al. Paraoxonase 2 is down-regulated by the Pseudomonas aeruginosa quorumsensing signal $\mathrm{N}$-(3oxododecanoyl)-L-homoserine lactone and attenuates oxidative stress induced by pyocyanin. Biochem J 2010; 426: 73-83.

15. Shih DM, Lusis AJ. The roles of PON1 and PON2 in cardiovascular disease and innate immunity. Curr Opin Lipidol 2009; 20: 288-292.

16. Shih DM, Xia YR, Wang XP, Wang SS, Bourquard N, Fogelman AM et al. Decreased obesity and atherosclerosis in human paraoxonase 3 transgenic mice. Circ Res 2007; 100: 1200-1207.

17. Shih DM, Gu L, Xia YR, Navab M, Li WF, Hama S et al. Mice lacking serum paraoxonase are susceptible to organophosphate toxicity and atherosclerosis. Nature 1998; 394: 284-287.

18. Ng CJ, Bourquard N, Grijalva V, Hama S, Shih DM, Navab M et al. Paraoxonase-2 deficiency aggravates atherosclerosis in mice despite lower apolipoprotein-B-containing lipoproteins: anti-atherogenic role for paraoxonase-2. J Biol Chem 2006; 281: 29491-29500.
19. Aviram M, Rosenblat M. Paraoxonases 1,2 , and 3 , oxidative stress, and macrophage foam cell formation during atherosclerosis development. Free Radic Biol Med 2004; 37: 1304-1316.

20. Li Y, Tang R, Xu H, Qiu M, Chen Q, Chen J et al. Discovery and analysis of hepatocellular carcinoma genes using cDNA microarrays. J Cancer Res Clin Oncol 2002; 128: 369-379.

21. Ribarska T, Ingenwerth M, Goering W, Engers R, Schulz WA. Epigenetic inactivation of the placentally imprinted tumor suppressor gene TFPI2 in prostate carcinoma. Cancer Genomics Proteomics 2010; 7: 51-60.

22. Pise-Masison CA, Radonovich M, Mahieux R, Chatterjee P, Whiteford C, Duvall J et al. Transcription profile of cells infected with human T-cell leukemia virus type I compared with activated lymphocytes. Cancer Res 2002; 62: 3562-3571.

23. Ross ME, Zhou X, Song G, Shurtleff SA, Girtman K, Williams WK et al. Classification of pediatric acute lymphoblastic leukemia by gene expression profiling. Blood 2003; 102: 2951-2959.

24. Kang H, Chen IM, Wilson CS, Bedrick EJ, Harvey RC, Atlas SR et al. Gene expression classifiers for relapse-free survival and minimal residual disease improve risk classification and outcome prediction in pediatric B-precursor acute lymphoblastic leukemia. Blood 2010; 115: 1394-1405.

25. Frank O, Brors B, Fabarius A, Li L, Haak M, Merk S et al. Gene expression signature of primary imatinib-resistant chronic myeloid leukemia patients. Leukemia 2006; 20: 1400-1407.

26. Horke S, Witte I, Wilgenbus P, Altenhofer S, Kruger M, Li H et al. Protective effect of paraoxonase-2 against endoplasmic reticulum stress-induced apoptosis is lost upon disturbance of calcium homoeostasis. Biochem J 2008; 416: 395-405.

27. Altenhofer S, Witte I, Teiber JF, Wilgenbus P, Pautz A, Li H et al. One enzyme, two functions: PON2 prevents mitochondrial superoxide formation and apoptosis independent from its lactonase activity. J Biol Chem 2010; 285: 24398-24403.

28. Devarajan A, Bourquard N, Hama S, Navab M, Grijalva V, Morvardi S et al. Paraoxonase 2 deficiency alters mitochondrial function and exacerbates the development of atherosclerosis. Antioxid Redox Signal 2010, doi:10.1089/ars.2010.3430.

29. Malhotra JD, Kaufman RJ. Endoplasmic reticulum stress and oxidative stress: a vicious cycle or a double-edged sword? Antioxid Redox Signal 2007; 9: 2277-2293.

30. Shen HM, Liu ZG. JNK signaling pathway is a key modulator in cell death mediated by reactive oxygen and nitrogen species. Free Radic Biol Med 2006; 40: 928-939.

31. Ott M, Robertson JD, Gogvadze V, Zhivotovsky B, Orrenius S. Cytochrome c release from mitochondria proceeds by a two-step process. Proc Natl Acad Sci USA 2002; 99: 1259-1263.

32. Kim R, Emi M, Tanabe K, Murakami S. Role of the unfolded protein response in cell death. Apoptosis 2006; 11: 5-13.

33. Ng CJ, Hama SY, Bourquard N, Navab M, Reddy ST. Adenovirus mediated expression of human paraoxonase 2 protects against the development of atherosclerosis in apolipoprotein E-deficient mice. Mol Genet Metab 2006; 89: 368-373.

34. Thorp E, Li G, Seimon TA, Kuriakose G, Ron D, Tabas I. Reduced apoptosis and plaque necrosis in advanced atherosclerotic lesions of Apoe-1- and Ldlr-I- mice lacking CHOP. Cell Metab 2009; 9: 474-481.

35. Lin JH, Li H, Yasumura D, Cohen HR, Zhang C, Panning B et al. IRE1 signaling affects cell fate during the unfolded protein response. Science 2007; 318: 944-949.

36. Urano F, Wang X, Bertolotti A, Zhang Y, Chung P, Harding HP et al. Coupling of stress in the ER to activation of JNK protein kinases by transmembrane protein kinase IRE1. Science 2000; 287: 664-666.

37. Shimizu Y, Hendershot LM. Oxidative folding: cellular strategies for dealing with the resultant equimolar production of reactive oxygen species. Antioxid Redox Signal2009; 11 : 2317-2331.

38. Fuhrman B, Gantman A, Khateeb J, Volkova N, Horke S, Kiyan J et al. Urokinase activates macrophage PON2 gene transcription via the PI3K/ROS/MEK/SREBP-2 signalling cascade mediated by the PDGFR-beta. Cardiovasc Res 2009; 84: 145-154.

39. Scaffidi C, Fulda S, Srinivasan A, Friesen C, Li F, Tomaselli KJ et al. Two CD95 (APO-1/ Fas) signaling pathways. Embo J 1998; 17: 1675-1687.

40. Chen X, Shen J, Prywes R. The luminal domain of ATF6 senses endoplasmic reticulum (ER) stress and causes translocation of ATF6 from the ER to the Golgi. J Biol Chem 2002; 277: $13045-13052$.

Cell Death and Disease is an open-access journal published by Nature Publishing Group. This work is licensed under the Creative Commons Attribution-Noncommercial-No Derivative Works 3.0 Unported License. To view a copy of this license, visit http://creativecommons.org/licenses/by-nc-nd/3.0/

Supplementary Information accompanies the paper on Cell Death and Disease website (http://www.nature.com/cddis) 